\title{
TAHSP:-
}

The Internet Joưnal of Allied Health Sciences and Practice

A Peer Reviewed Publication of the College of Health Care Sciences at Nova Southeastern University

Dedicated to allied health professional practice and education

http://ijahsp.nova.edu Vol. 11 No. 4 ISSN 1540-580X

\section{Evaluation of Factors that Increase the Severity of Dysmenorrhoea among University Female Students in Maiduguri, North Eastern Nigeria}

\author{
Roland Nnaemeka Okoro, PharmD1 \\ Helen Malgwi, B.Pharm ${ }^{1}$ \\ Glory Ogechi Okoro, BSc²
}

1. Faculty of Pharmacy, Department of Clinical Pharmacy and Pharmacy Administration, University of Maiduguri, Maiduguri, Borno State

2. Faculty of Biological Sciences, University of Maiduguri, Maiduguri, Borno State

Nigeria

CITATION: Okoro R, Malgwi H, Okoro G. Evaluation of Factors that Increase the Severity of Dysmenorrhoea among University Female Students in Maiduguri, North Eastern Nigeria. The Internet Journal of Allied Health Sciences and Practice. Oct 2013. Volume 11 Number 4.

\section{INTRODUCTION}

Dysmenorrhoea is defined as painful menses in women. ${ }^{1}$ Dysmenorrhoea is frequently encountered in young women around adolescence. ${ }^{2}$ It affects the quality of life (QOL) of women during reproductive age. The aetiology of primary dysmenorrhoea is not precisely understood, but most symptoms can be explained by the action of uterine prostaglandins, particularly PG F2a. ${ }^{3}$ It may be associated with other symptoms such as nausea, vomiting, diarrhoea, back pain, fatigue, headache, dizziness, and fainting. These symptoms could be very severe and social activity is very limited during menstruation, reducing quality of life in women. Severity of symptoms is usually assessed by grading of dysmenorrhoea as mild, moderate, and severe according to the degree of pain and analgesic requirement. ${ }^{4}$ Risk factors for dysmenorrhoea are early age at menarche ( $<12$ years), age $<20$ years, nulliparity, heavy or prolonged menstrual flow, smoking, positive family history, obesity, attempts to lose weight, depression/anxiety, disruption of social networks among others. A study on factors influencing the prevalence and severity of dysmenorrhoea in young women had been conducted in Sweden by Sundell et al. ${ }^{5}$ Another study was conducted by Okusanya et al on menstrual pain and associated factors amongst undergraduates of Ambrose Ali University Ekpoma, South- south, Nigeria. ${ }^{6}$ These studies were carried out in other areas; however, to the best of our knowledge, no study on the factors that influence severity of dysmenorrhoea has been conducted at the University of Maiduguri. Dysmenorrhoea is the leading cause of recurrent short-term school absence in adolescent girls and a common problem in women of reproductive age. ${ }^{7}$ Knowledge of the severity factors is important because of the potential for intervention. It is against this background that we undertook this study. The objectives of the study, therefore, were to evaluate the factors that increase the severity of dysmenorrhoea among university female students, and to determine if increased severity of dysmenorrhoea affects the academic performance of the participants.

\section{METHODS}

\section{Setting}

The study was conducted at the University of Maiduguri located at Bama road Maiduguri, Borno state, Nigeria. The university boasts of over 25,000 students from all over the world with specialized centers and units, a college of medicine, and faculties of Agriculture, Arts, Education, Engineering, Law, Social and Management Sciences, Pharmacy, Sciences, and Veterinary Medicine. Maiduguri lies between latitude $1150 \mathrm{~N}$ and longitude $1350 \mathrm{E}$ with an altitude of 345 meters above sea level and 
shares borders with three (3) West African countries, namely Chad, Niger, and Cameroun, whose indigenes often reside and trade in Maiduguri. The vegetation falls under the Sahel zone of West Africa. It is a semi-arid region with a short period of rainfall.

\section{Ethical Issues}

Ethical approval was obtained from the ethical committee of the University of Maiduguri Teaching hospital. Prior to the interview, the purpose of the study was clearly explained to the participants, and thereafter informed consent was obtained from them.

\section{Study Instrument}

The developed questionnaire was validated by first conducting a pilot-test on a sample of 20 participants. Thereafter, the questionnaire was modified in order to gather the required data. The modified questionnaire which consisted of 22 items with two parts was used for the study. The first part was designed to collect socio-demographic information from the participants. The second part was to gather information on various factors that may influence the severity of dysmenorrhoea.

\section{Data Collection}

A non-probability convenient method was used to select two hundred and eighty nine (289) participants from $1^{\text {st }}, 2^{\text {nd }}, 3^{\text {rd }}, 4^{\text {th }}$ and final year female students of faculties of Arts, Pharmacy, and Sciences, University of Maiduguri, in January 2012. Body mass index (BMI) was collected by measuring each participant's height and weight. Each participant's body weight was measured with domestic scales, whereas height was determined with a meter rule. No laboratory test was done to obtain the blood groups and genotypes; however, they were self-reported in the questionnaire.

\section{Data Analysis}

Statistical Package for Social Sciences (SPSS) version 16.0 for windows $®$ was used for data analysis. Pearson chi-square $\left(X^{2}\right)$ and Spearman correlation $\left(r_{s}\right)$ analyses were used to test for statistical significance. A p value of $\leq 0.05$ was considered statistically significant.

The intensity of dysmenorrhoea was scored using 3 grades consisting of grade 1 or mild (free of pain or painful, but can manage without analgesic; score 1), grade 2 or moderate (painful, requiring analgesic; score 2), and grade 3 or severe (painful, not relieved by analgesic; score 3$)^{4}$

BMI was calculated using the formula: body weight in kilograms divided by height in meters squared $\left(\mathrm{Kg} / \mathrm{m}^{2}\right)$. As per the "WHO The International Classification of adult underweight, overweight, and obesity according to BMI," those who had a BMI of 18.0 to $24.9 \mathrm{~kg} / \mathrm{m}^{2}$ were classified as normal weight, participants with BMI values that corresponded to a BMl of 25.0 to $29.9 \mathrm{~kg} / \mathrm{m}^{2}$ were classified as overweight (pre-obese), participants with BMI values that corresponded to an adult BMI of $30.0 \mathrm{~kg} / \mathrm{m}^{2}$ were classified as obese, and with BMl values that corresponded to $<18.0 \mathrm{~kg} / \mathrm{m}^{2}$ as underweight. ${ }^{8}$

Amount of menstrual flow per day was determined thus: 2 to 3 sanitary pads/day = Light flow; 5 to 6 sanitary pads/day $=$ Heavy flow.

\section{RESULTS}

A total number of 320 questionnaires were administered, of which 289 filled questionnaires were recovered giving a response rate of $90.31 \%$.

The Mean \pm Standard Deviation (SD) age of the participants was $22.2 \pm 3.1$ years. Severity of dysmenorrhoea correlated negatively with chronological age with significant association (Table 1). Severity of dysmenorrhoea also correlated negatively with no statistical significant association with age at menarche (Table 1). This finding could be a result of bias in participants' distribution where a few participants were within age at menarche of 10-11 years. Severity of dysmenorrhoea significantly positively correlated with heavy menstrual flow (Figure 1). Severity of dysmenorrhoea was decreased in parous young women compared with those who were nulliparous. Out of 10 mothers that participated in this study, none of them reported severe dysmenorrhoea, and dysmenorrhoea decreased with additional birth with significant association (Table 2).

The mean $\pm \mathrm{SD}$ of BMI was $22.8 \pm 4$.2. Dysmenorrhoea severity was distributed more in participants with low BMI than those with high BMI. There was a significant negative correlation between decreased BMI and severity of pain with $p<0.05$ (Figure 2). The implication of this finding is that participants with low BMl experienced more pain during their menstrual period than those with high BMI. There was no significant difference between severity of dysmenorrhoea and attempted weight loss (Table 3 ). 
There were no significant differences between severity of dysmenorrhoea and blood groups $\left(X^{2}=14.531 ; d f=12 ; p=0.268\right.$ ) (Figure 3) or genotypes $\left(X^{2}=15.953 ; d f=9 ; p=0.068\right)$ (Figure 4). There was no significant difference between severity of dysmenorrhoea and cigarette smoking (Table 4). Two hundred and fifty eight (89.3\%) participants reported that they had never drank alcohol. There was no significant difference between severity of dysmenorrhoea and alcohol consumption (Table 5). This finding could be due to representation bias in the alcohol drinking habit of the participants. There was no significant association $\left(X^{2}=2.443 ; d f=3 ; p=0.486\right)$ between severity of dysmenorrhoea and lack of physical exercise (Figure 5).

There was significant association $\left(X^{2}=16.146 ; d f=6 ; p=0.013\right.$ ) between severity of menstrual pain and sexual abuse (Table 6 ). There were no significant differences between severity of dysmenorrhoea and depression/anxiety, disruption of social network respectively (Table 6). The unequal representation could not allow for significant statistical analyses.

Ninety-two (31.85\%) and $36(12.5 \%)$ of the participants who suffered from moderate and severe dysmenorrhoea respectively did not experience poor academic performance. Whereas, $64(22.1 \%)$ and $50(17.3 \%)$ of the participants that suffered from moderate and severe dysmenorrhoea respectively experienced poor academic performance with a significant difference (Table 7).

\begin{tabular}{|c|c|c|c|c|c|c|c|}
\hline \multicolumn{8}{|c|}{ Table 1: A Cross tabulations of Age group, Age at Menarche by Severity of Dysmenorrhoea } \\
\hline \multirow{2}{*}{\multicolumn{2}{|c|}{ Variables }} & \multicolumn{4}{|c|}{ DYSMENORRHOEA SEVERITY } & \multirow[b]{2}{*}{ Total $(\%)$} & \multirow{2}{*}{$\begin{array}{l}\text { Spearman } \\
\text { Correlation } \\
\left(r_{s}\right)\end{array}$} \\
\hline & & No response $(\%)$ & Mild (\%) & Moderate (\%) & Severe (\%) & & \\
\hline \multirow{6}{*}{$\begin{array}{l}\text { Age group } \\
\text { Mean } \pm \\
\text { Standard } \\
\text { deviation (SD) } \\
\text { of Age (22.2 } \pm \\
3.1 \text { Years) }\end{array}$} & $\begin{array}{l}\text { No } \\
\text { response }\end{array}$ & $0(0.0)$ & $0(0.0)$ & $4(1.4)$ & $0(0.0)$ & $4(1.4)$ & \multirow{6}{*}{$\begin{array}{c}r_{s}=-0.123 \\
P=0.019\end{array}$} \\
\hline & $\leq 20$ & $4(1.4)$ & $5(1.7)$ & $34(11.8)$ & $29(10.0)$ & $72(24.9)$ & \\
\hline & $21-25$ & $1(0.3)$ & $23(8.0)$ & 103(35.6) & $46(15.9)$ & $173(59.9)$ & \\
\hline & $26-30$ & $4(1.4)$ & $7(2.4)$ & $15(5.2)$ & $7(2.4)$ & $33(11.4)$ & \\
\hline & $\geq 31$ & $0(0.0)$ & $3(1.0)$ & $0(0.0)$ & $4(1.4)$ & $7(2.4)$ & \\
\hline & Total & $9(3.1)$ & $38(13.1)$ & $156(54.0)$ & $86(29.8)$ & $289(100.0)$ & \\
\hline \multirow{7}{*}{$\begin{array}{l}\text { Age at } \\
\text { menarche } \\
\text { Mean } \pm S D \\
(13.8 \pm 2.0 \\
\text { years)[ranging } \\
\text { from } 11-19 \\
\text { years] }\end{array}$} & $\begin{array}{l}\text { No } \\
\text { response }\end{array}$ & $0(0.0)$ & $0(0.0)$ & $1(0.3)$ & $1(0.3)$ & $2(0.7)$ & \multirow{7}{*}{$\begin{array}{c}r_{s}=-0.086 \\
P=0.143\end{array}$} \\
\hline & $10-11$ & $0(0.0)$ & $0(0.0)$ & $8(2.8)$ & $3(1.0)$ & $11(3.8)$ & \\
\hline & $12-13$ & $0(0.0)$ & $20(6.9)$ & $62(21.5)$ & $37(12.8)$ & $119(41.2)$ & \\
\hline & $14-15$ & $4(1.4)$ & $12(4.2)$ & $61(21.1)$ & $36(12.5)$ & $113(39.1)$ & \\
\hline & $16-17$ & $3(1.0)$ & $4(1.4)$ & $20(6.9)$ & $7(2.4)$ & $34(11.8)$ & \\
\hline & 18-19 & $2(0.7)$ & $2(0.7)$ & $4(1.4)$ & $2(0.7)$ & $10(3.5)$ & \\
\hline & Total & $9(3.1)$ & $38(13.1)$ & $156(54.0)$ & $86(29.8)$ & $289(100.0)$ & \\
\hline
\end{tabular}


Table 2: A Cross tabulation of Are you a Mother? Number of Children by Dysmenorrhoea Severity

\begin{tabular}{|c|c|c|c|c|c|c|c|}
\hline & & \multicolumn{4}{|c|}{ DYSMENORRHOEA SEVERITY } & \multirow[b]{2}{*}{ Total $(\%)$} & \multirow{2}{*}{$\begin{array}{l}\text { Chi square } \\
\left(X^{2}\right) \text { Tests } \\
P \text { value }\end{array}$} \\
\hline \multicolumn{2}{|c|}{ Variable } & No response (\%) & Mild (\%) & Moderate (\%) & Severe (\%) & & \\
\hline \multirow[t]{4}{*}{$\begin{array}{l}\text { Are You a } \\
\text { Mother? }\end{array}$} & $\begin{array}{l}\text { No } \\
\text { response }\end{array}$ & $0(0.0)$ & $0(0.0)$ & $7(2.4)$ & $0(0.0)$ & $7(2.4)$ & \multirow{4}{*}{$P=0.018$} \\
\hline & No & $9(3.1)$ & $34(11.8)$ & $143(49.5)$ & $86(29.8)$ & $272(94.1)$ & \\
\hline & Yes & $0(0.0)$ & $4(1.4)$ & $6(2.1)$ & $0(0.0)$ & $10(3.5)$ & \\
\hline & Total & $9(3.1)$ & $38(13.1)$ & $156(54.0)$ & $86(29.8)$ & $289(100.0)$ & \\
\hline \multirow{6}{*}{$\begin{array}{l}\text { If Yes, how } \\
\text { many } \\
\text { children } \\
\text { have you } \\
\text { given birth } \\
\text { to? }\end{array}$} & $\begin{array}{l}\text { No } \\
\text { response }\end{array}$ & $1(10.0)$ & $0(0.0)$ & $0(0.0)$ & $0(0.0)$ & $1(10.0)$ & \multirow{6}{*}{$P=0.016$} \\
\hline & 1 & $0(0.0)$ & $0(0.0)$ & $4(40.0)$ & $0(0.0)$ & $4(40.0)$ & \\
\hline & 2 & $0(0.0)$ & $2(20.0)$ & $1(10.0)$ & $0(0.0)$ & $3(30,0)$ & \\
\hline & 3 & $0(0.0)$ & $1(10.0)$ & $0(0.0)$ & $0(0.0)$ & $1(10.0)$ & \\
\hline & 5 & $0(0.0)$ & $1(10.0)$ & $0(0.0)$ & $0(0.0)$ & $1(10.0)$ & \\
\hline & Total & $1(10.0)$ & $4(40.0)$ & $5(50.0)$ & $0(0.0)$ & $10(100.0)$ & \\
\hline
\end{tabular}

Figure 1. Dysmenorrhoea Severity by Amount of Menstrual Flow

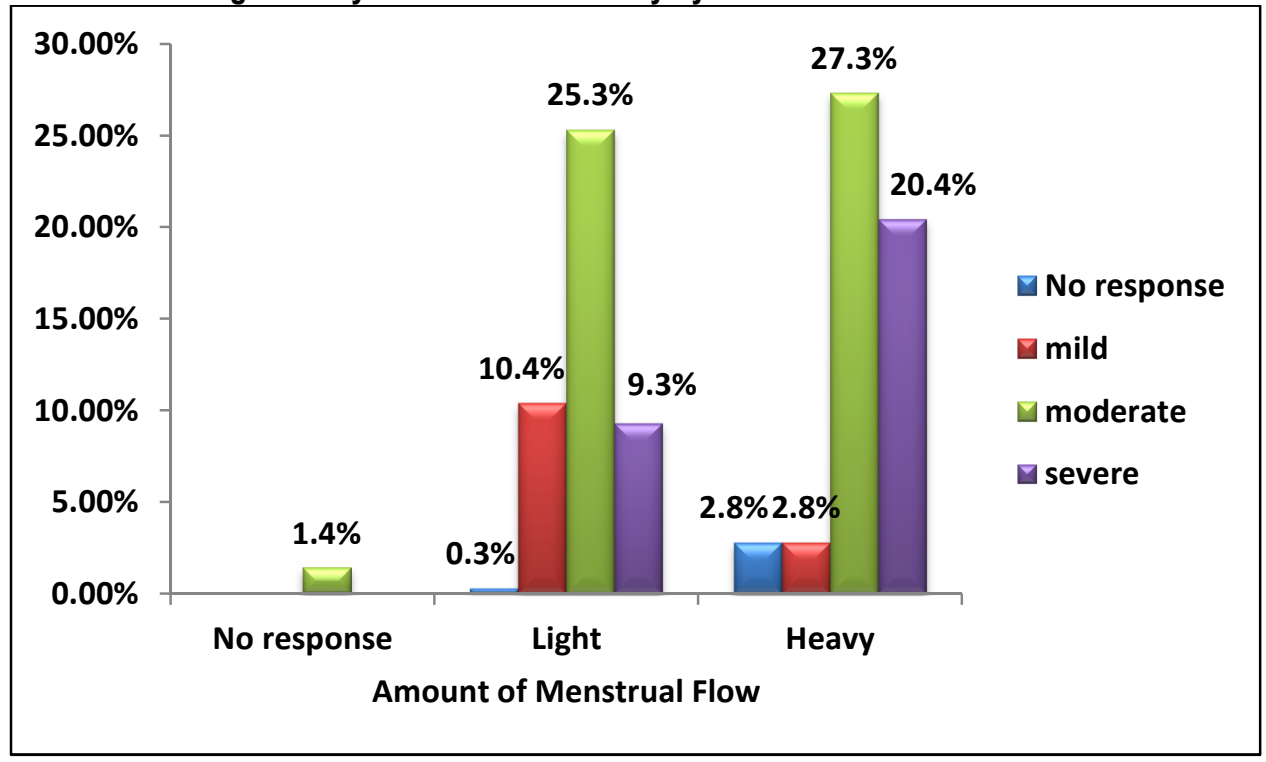

$r_{s}=0.220 ; p<0.05$ 
Table 3:A Cross tabulation of Attempted Weight Loss by Dysmenorrhoea Severity

\begin{tabular}{|c|c|c|c|c|c|c|c|}
\hline & & \multicolumn{4}{|c|}{ DYSMENORRHOEA SEVERITY } & \multirow[b]{2}{*}{ Total (\%) } & \multirow{2}{*}{$\begin{array}{l}X^{2} \text { test } \\
P \text { value }\end{array}$} \\
\hline \multicolumn{2}{|c|}{ Variable } & No response (\%) & Mild (\%) & Moderate (\%) & Severe (\%) & & \\
\hline \multirow{3}{*}{$\begin{array}{l}\text { Have you } \\
\text { attempted } \\
\text { to lose } \\
\text { weight? }\end{array}$} & No & $6(2.1)$ & $25(8.7)$ & $94(32.5)$ & $50(17.3)$ & $175(60.6)$ & \multirow{3}{*}{0.809} \\
\hline & Yes & $3(1.0)$ & $13(4.5)$ & $62(21.5)$ & $36(12.5)$ & $114(39.4)$ & \\
\hline & Total & $9(3.1)$ & $38(13.1)$ & $156(54.0)$ & $86(29.8)$ & $289(100.0)$ & \\
\hline \multirow{3}{*}{$\begin{array}{l}\text { If yes, } \\
\text { how } \\
\text { regular? }\end{array}$} & Occasionally & $3(2.6)$ & $12(10.5)$ & $52(45.6)$ & $27(23.7)$ & $94(82.5)$ & \multirow{3}{*}{0.777} \\
\hline & Very often & $0(0.0)$ & $1(0.9)$ & $10(8.8)$ & $9(7.9)$ & $20(17.5)$ & \\
\hline & Total & $3(2.6)$ & $13(11.4)$ & $62(54.4)$ & $36(31.6)$ & $114(100.0)$ & \\
\hline
\end{tabular}

Figure 2. Dysmenorrhoea Severity by Body Mass Index (BMI)

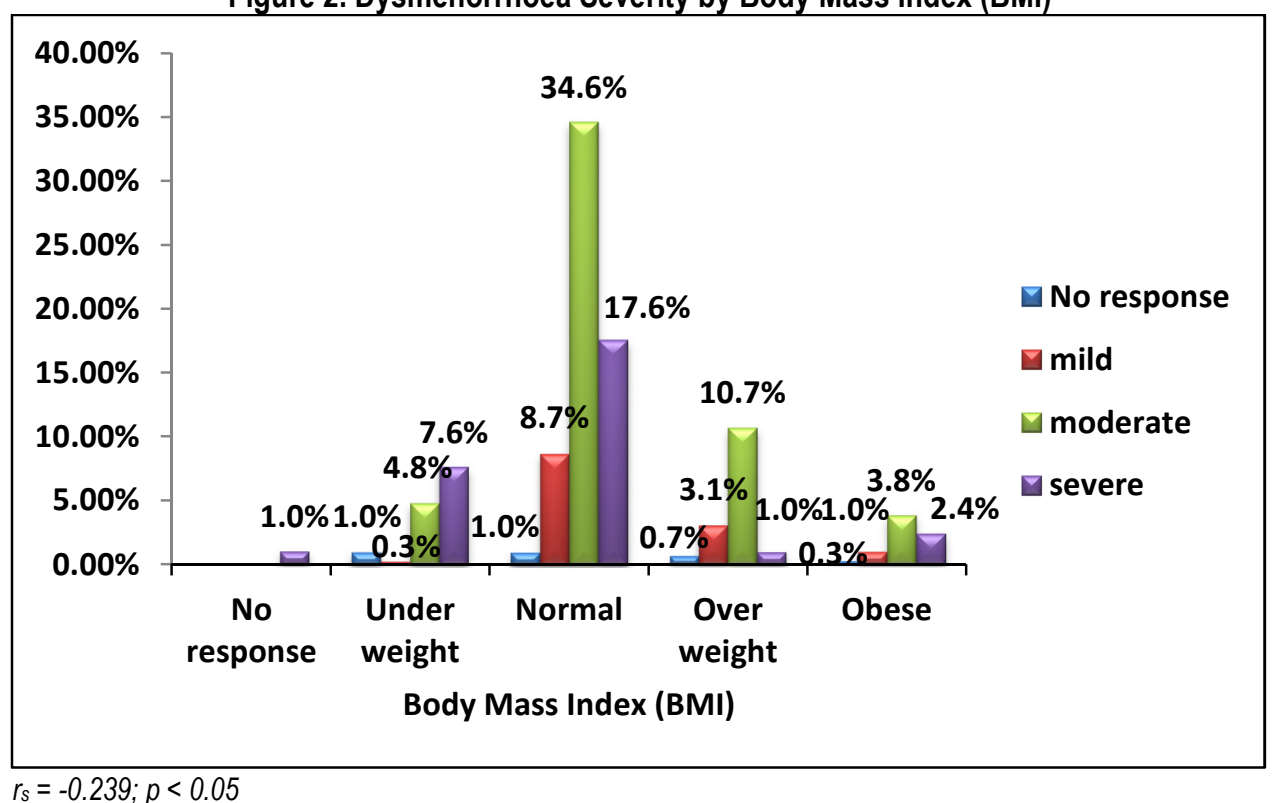

Table 4: A Cross tabulation of Cigarette smoking Habit by Dysmenorrhoea Severity

\begin{tabular}{|c|c|c|c|c|c|c|c|}
\hline \multirow{2}{*}{\multicolumn{2}{|c|}{ Variables }} & \multicolumn{4}{|c|}{ DYSMENORRHOEA SEVERITY } & \multirow[b]{2}{*}{ Total (\%) } & \multirow{2}{*}{$\begin{array}{l}X^{2} \text { Test } \\
P \text { value }\end{array}$} \\
\hline & & No response $(\%)$ & Mild (\%) & Moderate (\%) & Severe $(\%)$ & & \\
\hline \multirow{5}{*}{$\begin{array}{c}\text { Cigarette } \\
\text { smoking } \\
\text { habit }\end{array}$} & No response & $0(0.0)$ & $0(0.0)$ & $2(0.7)$ & $1(0.3)$ & $3(1.0)$ & \multirow{5}{*}{0.608} \\
\hline & Never smoked & $9(3.1)$ & $38(13.1)$ & $147(50.9)$ & $84(29.1)$ & $278(96.2)$ & \\
\hline & $\begin{array}{l}\text { Stopped } \\
\text { smoking }\end{array}$ & $0(0.0)$ & $0(0.0)$ & $7(2.4)$ & $1(0.3)$ & $8(2.8)$ & \\
\hline & Still smoking & $0(0.0)$ & $0(0.0)$ & $0(0.0)$ & $0(0.0)$ & $0(0.0)$ & \\
\hline & Total & $9(3.1)$ & $38(13.1)$ & $156(54.0)$ & $86(29.8)$ & $289(100.0)$ & \\
\hline \multirow{5}{*}{$\begin{array}{l}\text { If a stopped } \\
\text { smoker how } \\
\text { many sticks } \\
\text { of } \\
\text { cigarette(s) } \\
\text { did you } \\
\text { smoke in a } \\
\text { day? }\end{array}$} & No response & $3(37.5)$ & $0(0.0)$ & $0(0.0)$ & $0(0.0)$ & $3(37.5)$ & \multirow{5}{*}{0.760} \\
\hline & 1 & $0(0.0)$ & $0(0.0)$ & $3(37.5)$ & $0(0.0)$ & $3(37.5)$ & \\
\hline & 2 & $0(0.0)$ & $0(0.0)$ & $0(0.0)$ & $1(12.5)$ & $1(12.5)$ & \\
\hline & 3 & $0(0.0)$ & $0(0.0)$ & $1(12.5)$ & $0(0.0)$ & $1(12.5)$ & \\
\hline & Total & $3(37.5)$ & $0(0.0)$ & $4(50.0)$ & $1(12.5)$ & $8(100.0)$ & \\
\hline
\end{tabular}


Table 5: A Cross tabulation of Alcohol intake by Dysmenorrhoea Severity

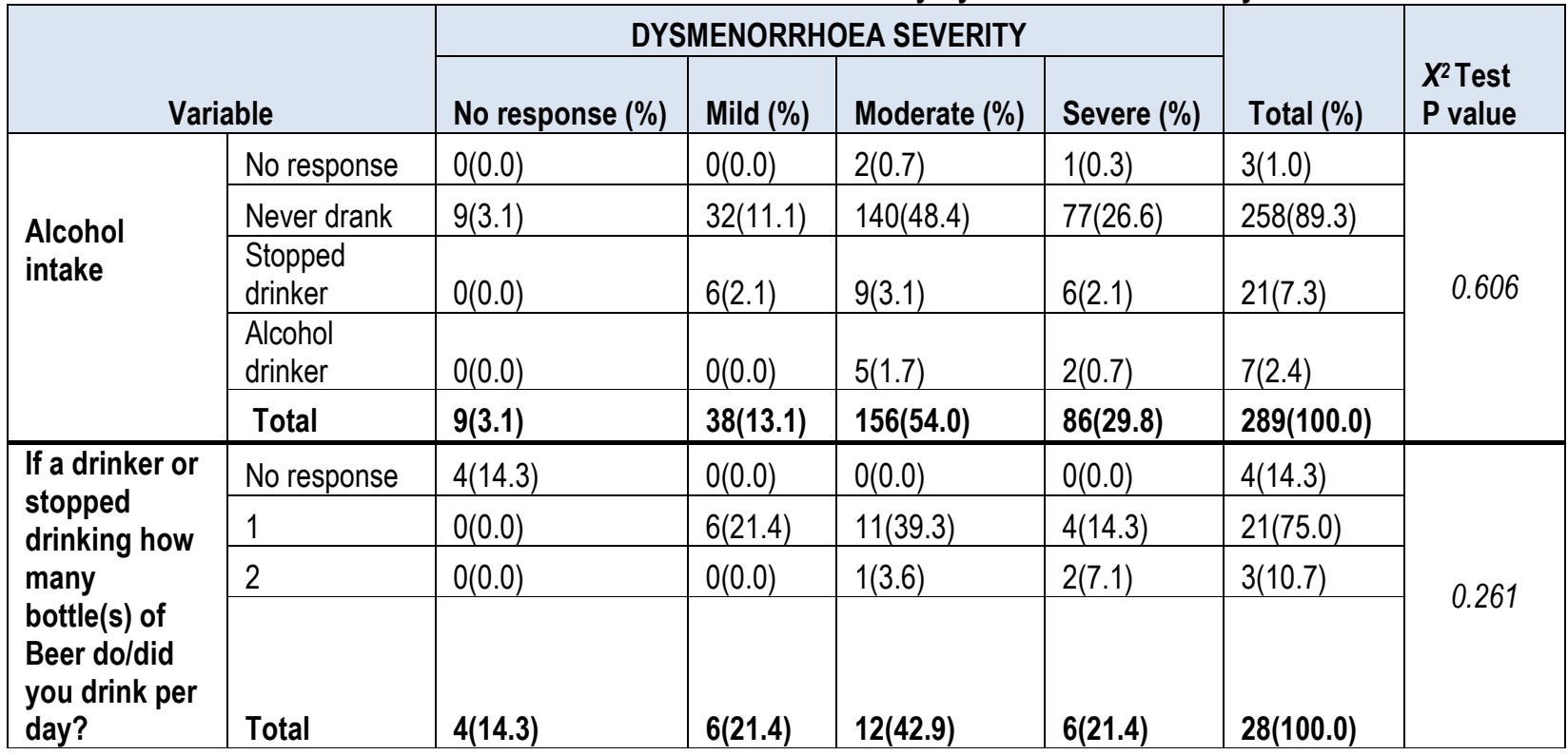

Table 6: A Cross tabulation of Psycho-social stress by Dysmenorrhoea Severity

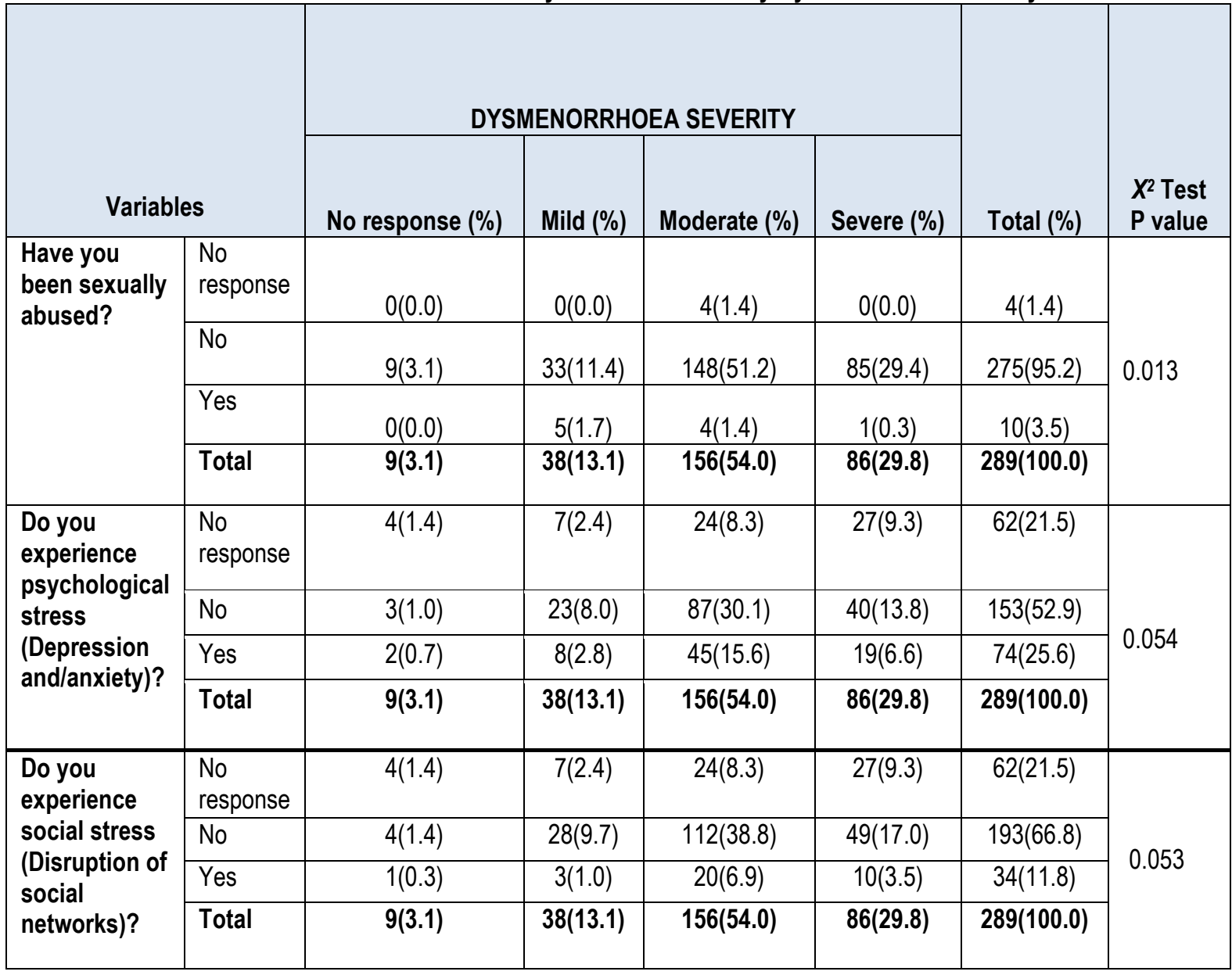


Figure 3: Dysmenorrhoea Severity by Blood groups

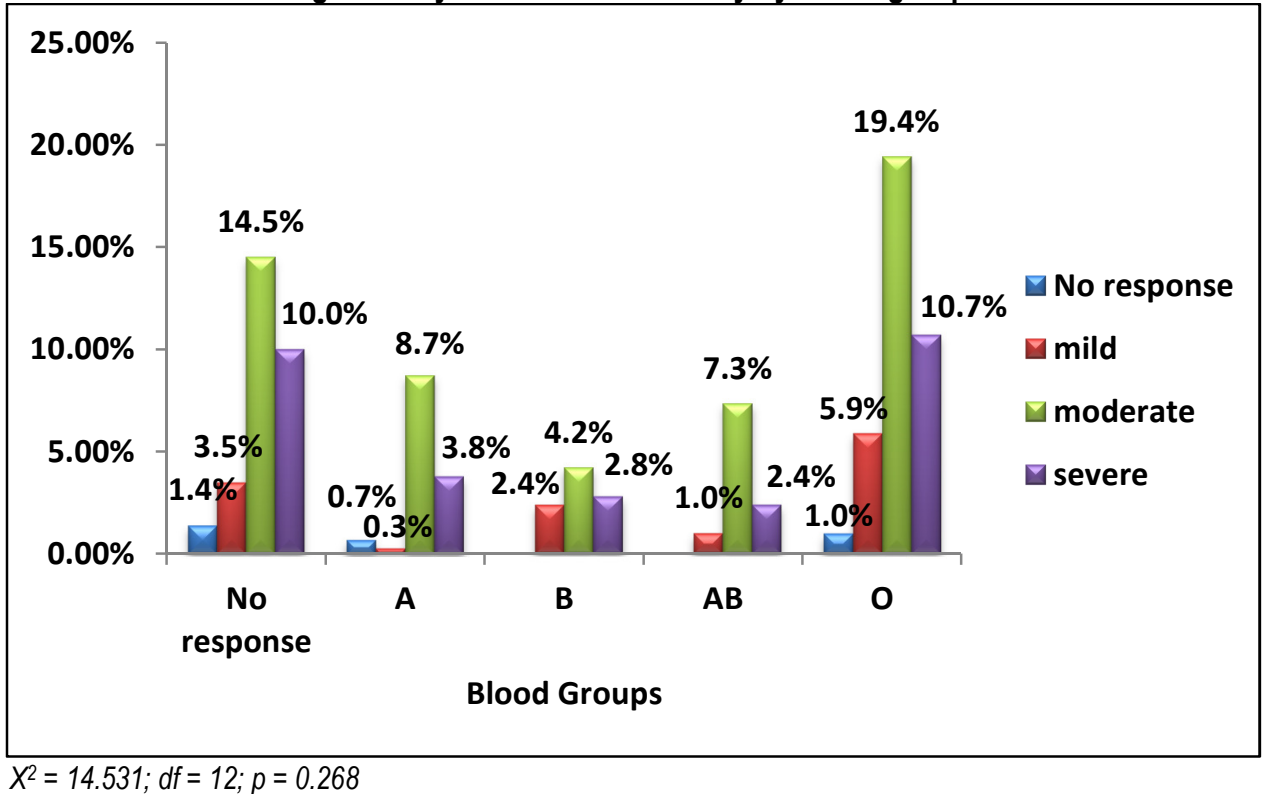

Figure 4: Dysmenorrhoea Severity by Genotypes

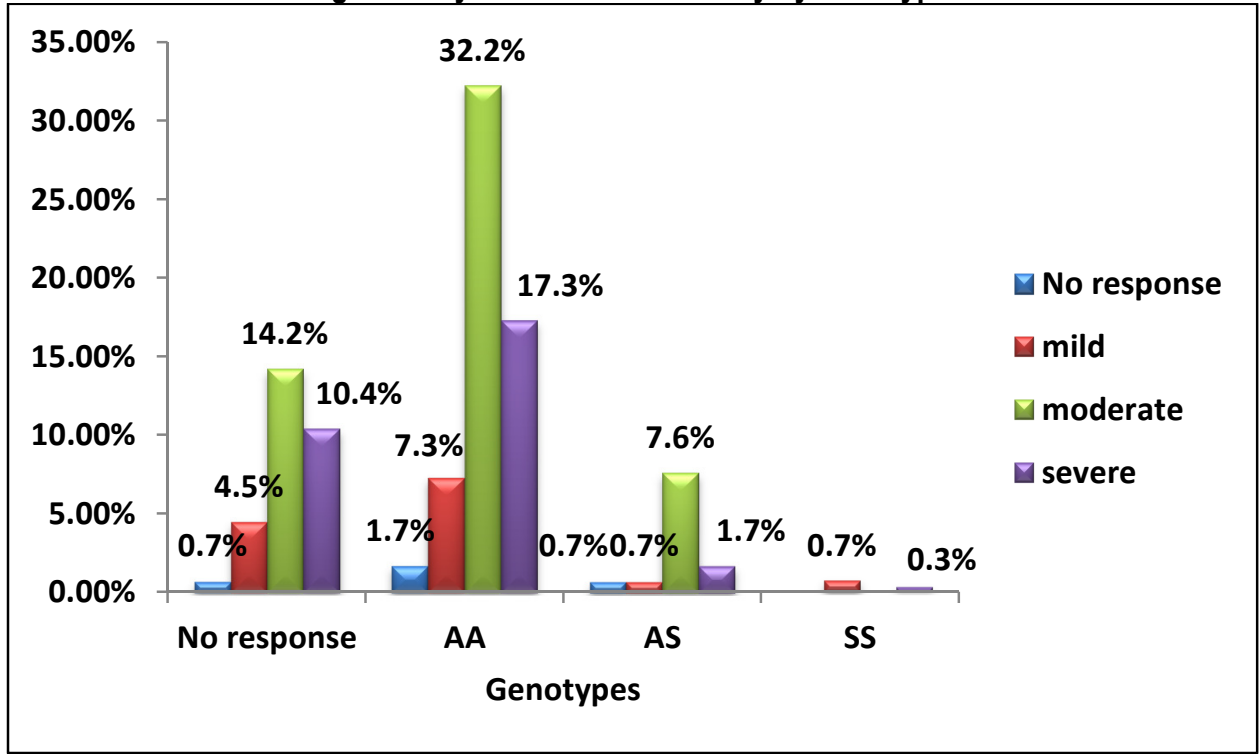

$X^{2}=15.953 ; d f=9 ; p=0.068$ 
Figure 5: Dysmenorrhoea Severity by Regular Physical Exercise

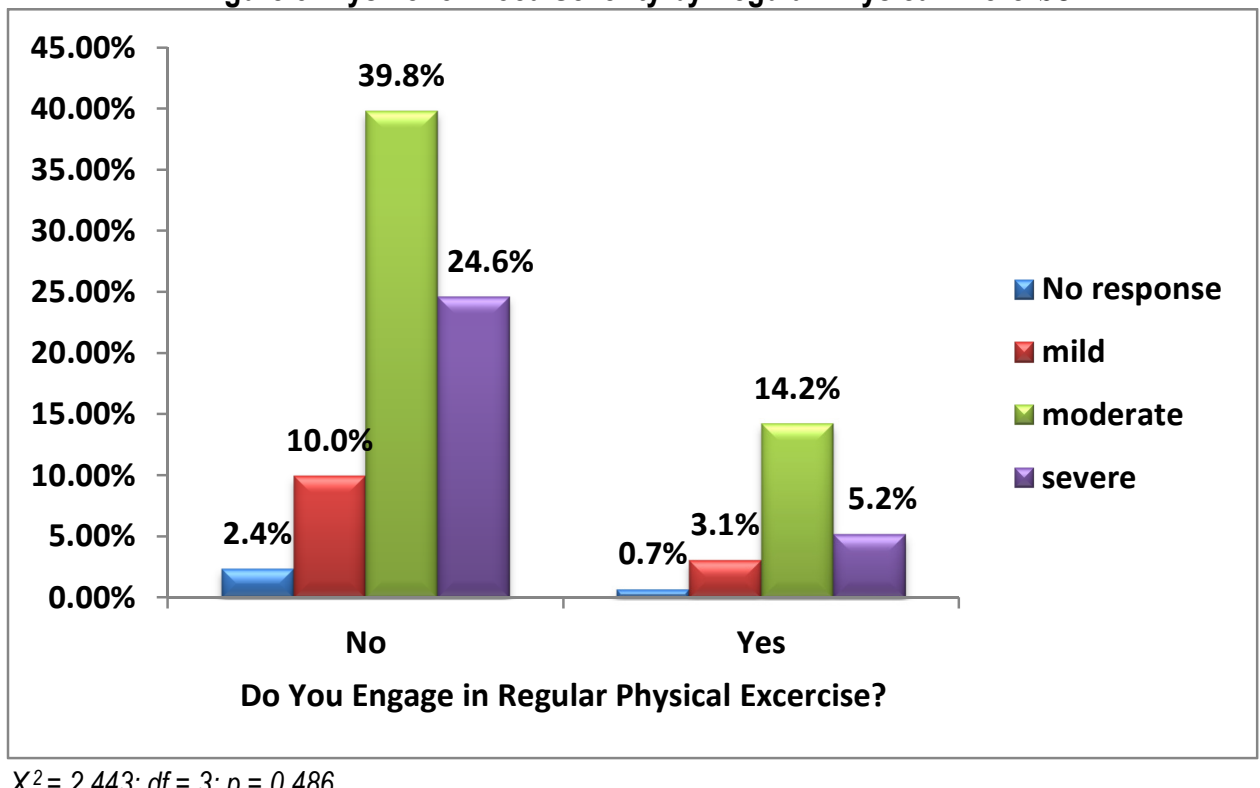

Table 7: A Cross tabulation of Do you Experience Poor Academic Performance due to Menstrual Pains? by Severity of Dysmenorrhoea

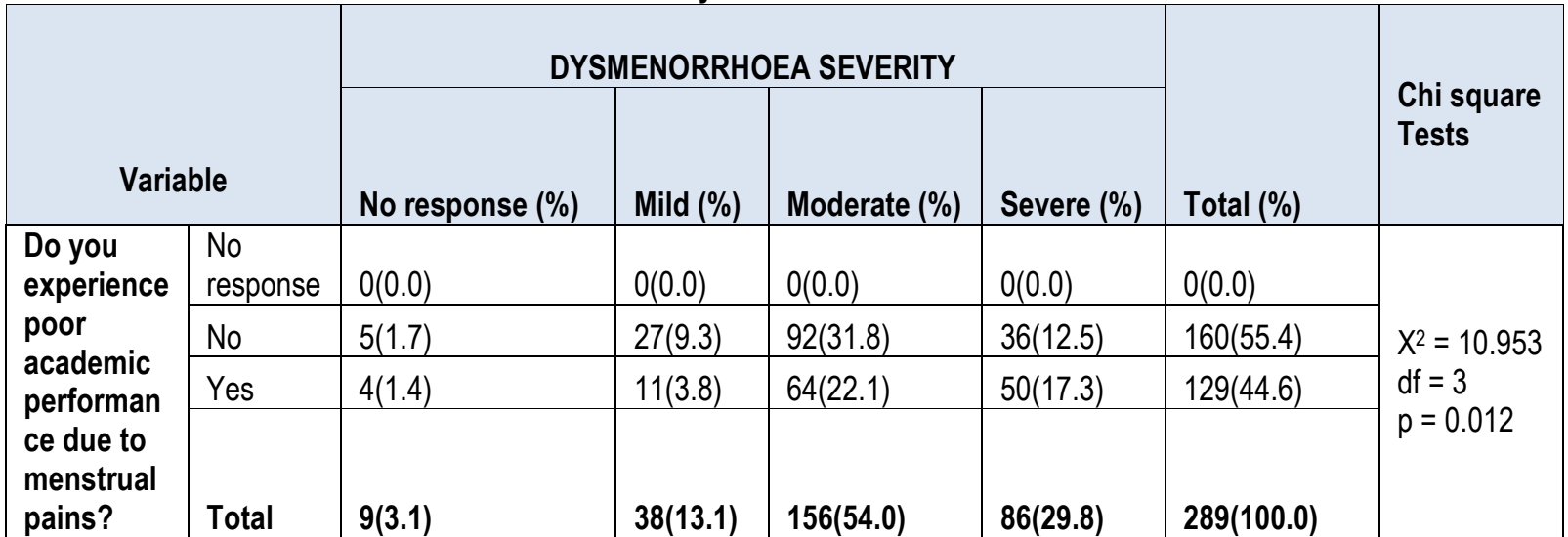

\section{DISCUSSION}

The majority of participants between the ages of 21 and 25 years had severe dysmenorrhoea followed by those less than 20 years of age. None of the participants that were mothers reported severe dysmenorrhoea. Most of the women with heavy menstrual flow had severe dysmenorrhoea. It was found to be more severe in women who were underweight than with overweight/obese women. There was no statistical difference in severity between women who had attempted to lose weight and those who had not. There were no significant differences between dysmenorrhoea severity and blood groups and genotypes respectively. The majority of the participants did not engage in regular physical exercise. Nevertheless, moderate dysmenorrhoea was suffered mostly by both the participants that engaged in regular physical exercise and those that did not. No significant associations were established between dysmenorrhoea severity with cigarette smoking and alcohol consumption respectively as a result of participants' representation bias. Sexual abuse was identified to influence the severity of dysmenorrhoea. There was a significant difference between participants that suffered from moderate and severe dysmenorrhoea respectively that experienced poor academic performance and those that did not.

Dysmenorrhoea is the most common gynaecological problem in women of reproductive age. ${ }^{1}$ In this study, severity of dysmenorrhoea decreased with increased chronological age with significant association. This observation may be attributed to the fact that these young women are likely to give birth as they advance in age. It is generally believed that parity decreases dysmenorrhoea and its severity. This study demonstrated that nulliparity influences dysmenorrhoea severity which is in 
concordance with the findings of a study which also found that severity of dysmenorrhoea was decreased in parous young women compared with those who were nulliparous as reported by Andersch and Milsom from an epidemiologic study of young women with dysmenorrhoea. ${ }^{9}$ An association was also found in a study on menstrual pain, health, and behaviour in girls by Teperi and Rimpela. ${ }^{10}$ These findings have shown that increased severity of dysmenorrhoea is more of a problem of the nulliparous women than the multiparous women. On the contrary, a study on dysmenorrhoea by Dawood and a study on cyclic pelvic pain and dysmenorrhoea by Smith found no evidence of decreased severity of dysmenorrhoea after parity.11, 12 The present study also demonstrated that early menarche increases the severity of dysmenorrhoea with no significant association. To support this finding, similar studies such as a study on influence of menstrual factors and dietary habits on menstrual pain in adolescent age by Balbi et al and a longitudinal study of risk factors for the occurrence, duration, and severity of menstrual cramps in a cohort of college women by Harlow and Park found significant correlation/association between early menarche and an increased severity of dysmenorrhoea. ${ }^{13,14}$ This shows that young females that started menstruating earlier, for example at age of less than 12 years, are at risk of increased severity of dysmenorrhoea. This could probably be explained by the fact that girls who attain menarche earlier have longer exposure to uterine prostaglandins, leading to higher severity of dysmenorrhoea.

Increased amount of menstrual flow directly increases the severity of dysmenorrhoea. ${ }^{1}$ Increased severity could be a result of an increase in the concentration of circulating prostaglandins in the copious menstrual fluid. The finding of this study is in line with the findings of an epidemiologic study of young women with dysmenorrhea by Andersch and Milsom and a study on influence of menstrual factors and dietary habits on menstrual pain in adolescence age by Balbi et al. $.9,13$ Underweight (low BMI) was found to increase the severity of dysmenorrhoea. The explanation is attributed to the fact that low weight, fat mass, low calorie intake, and eating disorders are speculated to disturb the pulsatile secretion of pituitary gonadotropins leading to an increase in dysmenorrhoea. A similar study done in Turkey by Ozerdogan et al also showed that the risk of dysmenorrhoea was higher in women who were underweight compared with overweight/obese women..$^{15}$ On the contrary, another study done by Harlow and Park demonstrated that the severity of dysmenorrhoea was positively associated with increased BMI. ${ }^{14} \mathrm{~A}$ study performed by Sundell et al on factors influencing the prevalence and severity of dysmenorrhoea in young women, an epidemiologic study of young women with dysmenorrhea by Andersch and Milsom, and a study conducted by Parazzini et al on cigarette smoking, alcohol consumption, and risk of primary dysmenorrhoea did not find any associations with obesity. $5,9,16$ Attempted weight loss was not found to increase the severity of dysmenorrhoea. The finding of this study is inconsistent with that of another study by Montero et al that showed that attempting to lose weight was significantly associated with increased menstrual pain. ${ }^{17}$

This study demonstrated that sexual abuse increases the severity of dysmenorrhoea. Young adolescent women who have been sexually abused will experience severe menstrual cramps. It has been reported that sexual abuse was associated with prolonged or heavy menstrual bleeding and medically unexplained dysmenorrhoea. ${ }^{18}$ "Women in the general population with common gynaecologic complaints (including dysmenorrhoea) are at a substantially increased risk of having a history of sexual assault."19 Therefore, in order to ascertain the severity of dysmenorrhoea during diagnosis, the history should include questions pertaining to sexual abuse.

Furthermore, blood groups and genotype according to this study did not influence the severity of dysmenorrhoea. However, an increase in prevalence was recorded among participants with blood group $O$ and genotype $A A$ respectively. Further studies are required to unravel the reasons for highest prevalence of dysmenorrhoea in adolescent females with blood group 0 and those with genotype $A A$.

Dysmenorrhoea itself is not life threatening, but it has a profoundly negative impact on a woman's day-to-day life. Moderate and severe menstrual pains interfere with women normal daily activities, especially when high performance is required (e.g. academic exams). The reasons for poor academic performance are inability to concentrate in class, inability to concentrate to study, inability to take test, and classes and tests missed because of school absenteeism.

\section{THE STUDY LIMITATION}

Self-reporting questionnaires rely only on the honesty of those reporting them.

\section{CONCLUSIONS}

The study concluded that severities of dysmenorrhoea are increased by young chronological age, nulliparity, sexual assault, heavy menstrual bleeding, low BMl, and earlier age at menarche. Although there was an association of severity of dysmenorrhoea with the age at menarche, this association was not found to be statistically significant. There were no associations of severity of dysmenorrhoea with blood groups, genotypes, physical exercise, and attempted weight loss. Increased severity of dysmenorrhoea was responsible for poor academic performance among these female students. 
The findings of this study thus indicate the magnitude of the problem and the need for healthcare providers to be more aware of the causes of dysmenorrhoea and factors that can aggravate it, to enable them to prescribe the appropriate pain relieving medications.

\section{ACKNOWLEDGEMENTS}

We wish to express our profound gratitude to the participants.

\section{REFERENCES}

1. French L. Dysmenorrhoea. Am Fam Physician. 2005; 71(2):285-91. [PMID 15686299]

2. Deligeoroglou E. Dysmenorrhea. Ann NY Acad Sci. 2000;900:237-44. [PMID 10818411]

3. Jaung CM, Yen MS, Horng HC, Cheng CY, Yuan CC, Chang CM. Natural progression of menstrual pain in nulliparous women at reproductive age: An observational study. J Chin Med Assoc. 2006;69(10):484-8. [PMID 17098673]

4. Fujiwara T. Skipping breakfast is associated with dysmenorrhoea in young women in Japan. Int J Food Sci Nutr. 2003;54(6):505-9. [PMID 14522696]

5. Sundell G, Milsom I, Andersch B. Factors influencing the prevalence and severity of dysmenorrhea in young women. $\mathrm{Br} \mathrm{J}$ Obstet Gynaecol.1990;97(7):588-94. [PMID 2390501]

6. Okusanya BO, Garba KK, Okome GB, Ohiosimuan O. Menstrual pain and associated factors amongst undergraduates of Ambrose Alli University Ekpoma, Edo State, Nigeria. Niger J Med. 2009;18(4):409-12. [PMID 20120147]

7. French L. Dysmenorrhoea in adolescents: diagnosis and treatment. Paediatr Drugs. 2008;10(1):1-7. [PMID 18162003]

8. World Health Organization. Obesity: preventing and managing the global epidemic Report of a WHO consultation on obesity. Technical report series, No 894. Geneva: World Health Organization; 2000.

9. Andersch B, Milsom I. An epidemiologic study of young women with dysmenorrhoea. Am J Obstet Gynecol. 1982;144(6):655-60. [PMID 7137249]

10. Teperi J, Rimpela M. Menstrual pain, health and behaviour in girls. Soc Sci Med.1989;29(2):163-9. [PMID 2787534]

11. Dawood MY. Dysmenorrhoea. Clin Obstet Gynecol. 1990;33(1):168-78. [PMID 2178834]

12. Smith RP. Cyclic pelvic pain and dysmenorrhoea. Obstet Gynecol Clin North Am. 1993;20(4):753-64. [PMID 8115089]

13. Balbi $C$, Musone R, Menditto $A$, et al. Influence of menstrual factors and dietary habits on menstrual pain in adolescence age. Eur J Obstet Gynecol Reprod Biol. 2000;91(12):143-8. [PMID 10869786]

14. Harlow SD, Park M. A longitudinal study of risk factors for the occurrence, duration and severity of menstrual cramps in a cohort of college women. Br J Obstet Gynaecol.1996;103(11):1134-42. [PMID 8917003]

15. Ozerdogan N, Sayiner D, Ayranci U, Unsal A, Giray S. Prevalence and predictors of dysmenorrhoea among students at a university in Turkey. Int J Gynaecol Obstet. 2009;107(1):39-43. doi: 10.1016/j.ijgo.2009.05.010. [PMID 19539288]

16. Parazzini F, Tozzi L, Mezzopane R, et al. Cigarette smoking, alcohol consumption, and risk of primary dysmenorrhoea. Epidemiology.1994;5(4):469-72. [PMID 7918820]

17. Montero $P$, Bernis $C$, Fernandes $V$, Castro $S$. Influence of body mass index and slimming habits on menstrual pain and cycle irregularity.J Biosoc Sci.1996;28(3):315-23. [PMID 8698711]

18. Golding JM. Sexual assault history and women's reproductive and sexual health. Psychol Women Q.1996;20:101-21. [PMID 12296010]

19. Golding JM, Wilsnack SC, Learman LA. Prevalence of sexual assault history among women with common gynecologic symptoms. Am J Obstet Gynecol. 1998;179(4):1013-9. [PMID 9790390] 